\title{
Cardiac acoustic biomarkers as surrogate markers to diagnose the phenotypes of pulmonary hypertension: an exploratory study
}

\author{
Nobuhide Yamakawa ${ }^{1} \cdot$ Norihiko Kotooka $^{2} \cdot$ Tomoyuki Kato $^{1} \cdot$ Tatsuhiko Kuroda $^{1} \cdot$ Koichi Node $^{2}$
}

Received: 12 February 2021 / Accepted: 10 September 2021 / Published online: 1 October 2021

(c) The Author(s) 2021

\begin{abstract}
Pulmonary hypertension $(\mathrm{PH})$ is commonly associated with left heart disease. In this retrospective study, using the database of a clinical study conducted between January 2008 and July 2008, the phenotypes of PH were classified using non-invasive cardiac acoustic biomarkers (CABs) and compared with classification by echocardiography. Records with same-day measurement of acoustic cardiography and right heart catheterization (RHC) parameters were included; cases with congenital heart disease were excluded. Using the RHC measurements, $\mathrm{PH}$ was classified as pre-capillary PH (Prec-PH), isolated postcapillary PH (Ipc-PH), and combined pre-capillary and post-capillary PH (Cpc-PH). The first, second, third, and fourth heart sounds (S1, S2, S3, and S4) were quantified as CABs (intensity, complexity, and strength). Forty subjects were selected: 5 had Prec-PH, 5 had Ipc-PH, 8 had Cpc-PH, and 22 had No-PH. CABs were significantly correlated with RHC measurements, with significant differences among phenotypes. Phenotype classification was performed using various CABs, and the diagnostic performance as assessed by the area under the receiver operating characteristic curve was $0.674-0.720$ for Prec-PH, 0.657-0.807 for Ipc-PH, and 0.742 for Cpc-PH. High negative and low positive predictive values for phenotype identification were observed. CABs may provide an ambulatory measurement method with home-monitoring friendliness which is more convenient than standard examinations to identify presence of $\mathrm{PH}$ and its phenotypes.
\end{abstract}

Keywords Cardiac acoustic biomarkers $\cdot$ Echocardiography $\cdot$ Phenotype $\cdot$ Pulmonary hypertension $\cdot$ Right heart catheterization

\section{Introduction}

Pulmonary hypertension (PH) is commonly associated with left heart disease and categorized as $\mathrm{PH}$ due to left heart disease (PH-LHD) [1]. The majority of PH-LHD patients are reported to have heart failure (HF), with both reduced and preserved ejection fraction [2], which is a well-known pathological condition for functional and structural impairment in the heart [3]. The structure and hemodynamic status of the pulmonary circulation are largely affected by both pulmonary and cardiac failure, possibly leading to a poor prognosis due to remodeling in the right ventricle, as well as in the pulmonary artery and veins [4]. Diagnostic and therapeutic

Koichi Node

node@cc.saga-u.ac.jp

1 Healthcare R\&D Center, Asahi Kasei Corporation, 1-1-2 Yurakucho, Chiyoda-ku, Tokyo 100-0006, Japan

2 Department of Cardiovascular Medicine, Saga University, 5-1-1 Nabeshima, Saga, Saga 849-8501, Japan strategies for PH-LHD are, however, not yet established [5]; therefore, its management is one of the clinical challenges for both PH and HF experts.

$\mathrm{PH}$ is mainly characterized by increased pulmonary artery pressure (PAP) on right heart catheterization (RHC) [6]. RHC provides precise information not only for $\mathrm{PH}$ diagnosis, but also to differentiate $\mathrm{PH}$ phenotypes [pre-capillary $\mathrm{PH}$ (Prec-PH), isolated post-capillary PH (Ipc-PH), and combined pre- and post-capillary $\mathrm{PH}(\mathrm{Cpc}-\mathrm{PH})]$ when other hemodynamic parameters, such as pulmonary artery wedge pressure (PAWP) and pulmonary vascular resistance (PVR), are available [7]. PH-LHD is categorized as post-capillary $\mathrm{PH}$, and in the $\mathrm{PH}$ with HF population, $14 \%$ of systolic and $12 \%$ of diastolic HF cases were reported to have $\mathrm{Cpc}-\mathrm{PH}$, and the rest had Ipc-PH [8]. Since the pathophysiology and prognosis of Cpc-PH are distinct from those of Ipc-PH, differentiation of these two phenotypes by measuring PVR is clinically important [8]. Only PAP has been a target of continuous monitoring for HF patients by an implantable device to decrease the risk of re-hospitalization [9], but no other 


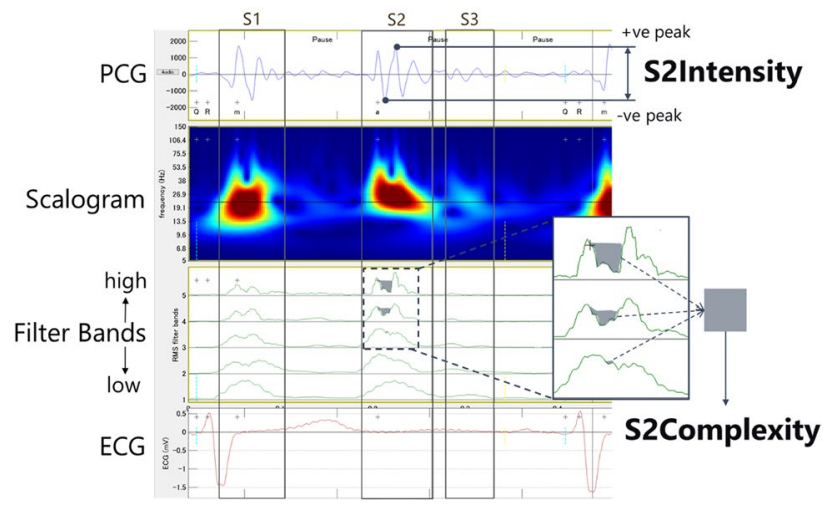

Fig. 1 Visual description of SnIntensity and SnComplexity as CABs. In this example, the patient has pre-capillary $\mathrm{PH}$, and CABs shows S2Intensity $=5.4$ and S2Complexity $=9.8$, which are high in comparison with the control (No-PH) population. The same principle can be applied to the other intensity and complexity values, e.g., S1Intensity and S1Complexity. The scalogram visualizes the changes of frequency components with time and aids users to observe abnormalities in heart sounds. The phonocardiogram (PCG) signal is decomposed into five different frequency components in the filter bands row

hemodynamic parameters to classify $\mathrm{PH}$ can be measured by such monitoring. Although heart and pulmonary function can be evaluated by measurement of PAP, providing much clinically useful information, invasive procedures are needed, which involve risk to the patients $[10,11]$.

To estimate PAP for PH diagnosis without invasive technology, surrogate methods using echocardiography measurements have been attempted [12,13]. Moreover, validation studies to distinguish the phenotypes, pre-capillary versus post-capillary $\mathrm{PH}$, using echocardiographic assessment have been performed [14-16]. Although echocardiography is a non-invasive and inexpensive method to estimate PAP and other hemodynamic parameters, the correlation and the specificity in the previous reports were insufficient for $\mathrm{PH}$ diagnosis and phenotyping [17-20].

Acoustic cardiography is a technology for quantifying heart and pulmonary status by non-invasive measurement of cardiohemic vibrations (cardiac cavities, valves, and blood) with simultaneously recorded electrocardiograms (ECGs) and automatic calculation of cardiac acoustic biomarkers (CABs) [21]. Non-invasive estimation of PAP using CABs has been previously reported $[22,23]$. The relationship between the second heart sound measured by acoustic cardiography and PAP measured by RHC was evaluated crosssectionally in a pre-capillary $\mathrm{PH}$ population, e.g., pulmonary artery hypertension (PAH), but a comprehensive evaluation of patients with post-capillary PH or PH-LHD and its specific phenotypes, Ipc- and Cpc-PH, has not been performed.

In this analysis, the correlations between measurement parameters of RHC and CABs were evaluated, and the diagnostic accuracy for different phenotypes of $\mathrm{PH}$ was evaluated.

\section{Materials and methods}

\section{Subjects}

The present study was based on a retrospective analysis using the database from a study conducted at the University of Utah Health Sciences Center and The Veterans Administration Salt Lake City Health Care System between January

Table 1 Subjects' characteristics

\begin{tabular}{|c|c|c|c|c|c|c|}
\hline \multirow[t]{2}{*}{ Item } & & \multicolumn{4}{|l|}{ Type of PH } & \multirow[t]{2}{*}{$p$} \\
\hline & & Prec-PH $(n=5)$ & Ipc-PH $(n=5)$ & Cpc-PH $(n=8)$ & No-PH $(n=22)$ & \\
\hline Age & years & $55.8 \pm 16.7$ & $66.0 \pm 12.0$ & $60.8 \pm 13.0$ & $52.4 \pm 16.5$ & 0.271 \\
\hline BMI & $\mathrm{kg} / \mathrm{m}^{2}$ & $27.2 \pm 10.3$ & $32.2 \pm 9.6$ & $28.1 \pm 6.9$ & $28.9 \pm 6.0$ & 0.703 \\
\hline Sex & Male (\%) & $1(20.0)$ & $3(60.0)$ & $5(62.5)$ & $17(77.3)$ & 0.117 \\
\hline Classification & Inpatient (\%) & $1(20.0)$ & $1(20.0)$ & $5(62.5)$ & $5(22.7)$ & 0.196 \\
\hline Current smoker & Yes $(\%)$ & $0(0.0)$ & $1(20.0)$ & $0(0.0)$ & $0(0.0)$ & 0.226 \\
\hline NYHA class & 0/I/II/III/IV & $1 / 3 / 1 / 0 / 0$ & $1 / 2 / 1 / 0 / 1$ & $1 / 0 / 4 / 2 / 1$ & $9 / 9 / 2 / 2 / 0$ & 0.053 \\
\hline Hypertension & Yes $(\%)$ & $3(60.0)$ & $4(80.0)$ & $5(62.5)$ & $20(90.9)$ & 0.230 \\
\hline Diabetes & Yes $(\%)$ & $1(20.0)$ & $2(40.0)$ & $3(37.5)$ & $6(27.3)$ & 0.857 \\
\hline Dyslipidemia & Yes $(\%)$ & $3(60.0)$ & $4(80.0)$ & $5(62.5)$ & $19(86.4)$ & 0.422 \\
\hline Obstructive sleep apnea & Yes $(\%)$ & $1(20.0)$ & $2(40.0)$ & $3(37.5)$ & $4(18.2)$ & 0.614 \\
\hline Coronary artery disease & Yes $(\%)$ & $1(20.0)$ & $2(40.0)$ & $4(50.0)$ & $8(36.4)$ & 0.847 \\
\hline
\end{tabular}

Data presented as means \pm SD or numbers $(\%)$

$P H$ pulmonary hypertension, $P r e c-P H$ pre-capillary $\mathrm{PH}, I p c-P H$ isolated post-capillary $\mathrm{PH}, C p c-P H$ combined pre- and post-capillary $\mathrm{PH}$, NYHA New York Heart Association function class

$p$ value represents difference between types of $\mathrm{PH}$ 
Table 2 Correlations between RHC parameters and CABs

\begin{tabular}{|c|c|c|c|c|c|}
\hline \multicolumn{2}{|l|}{ Parameter } & \multicolumn{4}{|c|}{ Measurement site } \\
\hline \multirow[t]{2}{*}{ RHC } & \multirow[t]{2}{*}{ CABs } & \multicolumn{2}{|l|}{$3 \mathrm{~L}$} & \multicolumn{2}{|l|}{ V4 } \\
\hline & & $r$ & $p$ & $r$ & $p$ \\
\hline \multirow[t]{8}{*}{ Mean PAP $(\mathrm{mmHg})$} & S1Intensity & 0.075 & 0.646 & 0.075 & 0.647 \\
\hline & S2Intensity & 0.253 & 0.116 & 0.255 & 0.113 \\
\hline & S3Intensity & 0.206 & 0.202 & 0.277 & 0.084 \\
\hline & S4Intensity & 0.220 & 0.185 & 0.261 & 0.108 \\
\hline & S1Complexity & -0.014 & 0.933 & -0.094 & 0.565 \\
\hline & S2Complexity & 0.300 & 0.060 & 0.426 & 0.006 \\
\hline & S3Strength & 0.176 & 0.278 & 0.347 & 0.028 \\
\hline & S4Strength & 0.196 & 0.238 & 0.070 & 0.674 \\
\hline \multirow[t]{8}{*}{ PAWP (mmHg) } & S1Intensity & -0.164 & 0.313 & -0.090 & 0.579 \\
\hline & S2Intensity & 0.038 & 0.817 & 0.090 & 0.583 \\
\hline & S3Intensity & 0.276 & 0.085 & 0.344 & 0.030 \\
\hline & S4Intensity & 0.104 & 0.534 & 0.145 & 0.379 \\
\hline & S1Complexity & -0.077 & 0.636 & -0.178 & 0.272 \\
\hline & S2Complexity & 0.031 & 0.850 & 0.083 & 0.611 \\
\hline & S3Strength & 0.499 & 0.001 & 0.581 & $<0.001$ \\
\hline & S4Strength & 0.151 & 0.367 & 0.065 & 0.695 \\
\hline \multirow[t]{8}{*}{ PVR (dynes s cm ${ }^{-5}$ ) } & S1Intensity & 0.074 & 0.651 & 0.115 & 0.479 \\
\hline & S2Intensity & 0.182 & 0.261 & 0.193 & 0.233 \\
\hline & S3Intensity & 0.026 & 0.876 & 0.124 & 0.447 \\
\hline & S4Intensity & 0.172 & 0.301 & 0.233 & 0.154 \\
\hline & S1Complexity & -0.073 & 0.653 & -0.155 & 0.339 \\
\hline & S2Complexity & 0.398 & 0.011 & 0.474 & 0.002 \\
\hline & S3Strength & -0.063 & 0.700 & 0.074 & 0.652 \\
\hline & S4Strength & 0.238 & 0.150 & 0.177 & 0.283 \\
\hline \multirow[t]{8}{*}{$\mathrm{CI}\left(1 / \mathrm{min} / \mathrm{m}^{2}\right)$} & S1Intensity & 0.318 & 0.049 & 0.256 & 0.116 \\
\hline & S2Intensity & 0.177 & 0.281 & 0.153 & 0.353 \\
\hline & S3Intensity & 0.031 & 0.852 & -0.041 & 0.803 \\
\hline & S4Intensity & 0.077 & 0.653 & 0.109 & 0.516 \\
\hline & S1Complexity & 0.193 & 0.239 & 0.347 & 0.031 \\
\hline & S2Complexity & 0.042 & 0.799 & 0.046 & 0.779 \\
\hline & S3Strength & -0.207 & 0.207 & -0.298 & 0.066 \\
\hline & S4Strength & -0.157 & 0.354 & -0.054 & 0.748 \\
\hline
\end{tabular}

$R H C$ right heart catheterization, $C A B s$ cardiac acoustic biomarkers, mean PAP mean pulmonary arterial pressure, $P A W P$ pulmonary artery wedge pressure, $P V R$ pulmonary vascular resistance, $C I$ cardiac index
2008 and July 2008. All patients referred for RHC, as well as ICU inpatients with a Swan-Ganz pulmonary artery catheter inserted, in the hospitals were included. Hemodynamically unstable patients, those with a high degree of noise in the vicinity of their chest, e.g. positive pressure ventilation, and those with congenital heart disease (CHD) were excluded.

This study was conducted in compliance with the Declaration of Helsinki. The study protocol was reviewed and approved by the ethics committee of Saga University, Japan. Written, informed consent was obtained from all subjects before measurement of baseline data.

\section{Diagnosis of pulmonary hypertension}

The diagnosis and the phenotypes of $\mathrm{PH}$ were classified by mean PAP, PAWP, and PVR by RHC in accordance with the updated clinical classification of PH [7]: Prec-PH (mean PAP $>20 \mathrm{mmHg}$, PAWP $\leq 15 \mathrm{mmHg}$, and PVR $\geq 3$ Wood Units); Ipc-PH (mean PAP $>20 \mathrm{mmHg}$, PAWP $>15 \mathrm{mmHg}$, and PVR $<3$ Wood Units; Cpc-PH (mean PAP $>20 \mathrm{mmHg}$, PAWP $>15 \mathrm{mmHg}$, and PVR $\geq 3$ Wood Units), and No-PH. Since the measurement values of PVR were recorded in dynes $\mathrm{s} \mathrm{cm}^{-5}$, the threshold of 3 Wood Units was substituted by 240 dynes $\mathrm{s} \mathrm{cm}^{-5}$. 
Table 3 RHC parameters by type of PH

\begin{tabular}{|c|c|c|c|c|c|}
\hline RHC & Type of PH & Mean & SD & $n$ & $p$ vs none \\
\hline \multirow[t]{4}{*}{ Mean PAP $(\mathrm{mmHg})$} & No-PH & 16.2 & 4.1 & 22 & \\
\hline & Prec-PH & 31.2 & 6.9 & 5 & $<0.001$ \\
\hline & Ipc-PH & 32.2 & 5.5 & 5 & $<0.001$ \\
\hline & Cpc-PH & 40.5 & 7.3 & 8 & $<0.001$ \\
\hline \multirow[t]{4}{*}{ PAWP $(\mathrm{mmHg})$} & No-PH & 9.0 & 3.7 & 22 & \\
\hline & Prec-PH & 9.0 & 5.5 & 5 & 0.982 \\
\hline & Ipc-PH & 22.4 & 4.6 & 5 & $<0.001$ \\
\hline & Cpc-PH & 19.5 & 3.6 & 8 & $<0.001$ \\
\hline \multirow[t]{4}{*}{ PVR (dynes s cm ${ }^{-5}$ ) } & No-PH & 117.6 & 53.1 & 22 & \\
\hline & Prec-PH & 332.3 & 134.7 & 5 & $<0.001$ \\
\hline & Ipc-PH & 157.1 & 78.0 & 5 & 0.415 \\
\hline & Cpc-PH & 428.4 & 160.2 & 8 & $<0.001$ \\
\hline \multirow[t]{4}{*}{$\mathrm{CI}\left(1 / \mathrm{min} / \mathrm{m}^{2}\right)$} & No-PH & 2.7 & 0.8 & 21 & \\
\hline & Prec-PH & 2.6 & 0.5 & 5 & 0.629 \\
\hline & Ipc-PH & 2.7 & 1.0 & 5 & 0.975 \\
\hline & Cpc-PH & 1.9 & 0.2 & 8 & 0.006 \\
\hline
\end{tabular}

$R H C$ right heart catheterization, mean $P A P$ mean pulmonary arterial pressure, $P A W P$ pulmonary artery wedge pressure, $P V R$ pulmonary vascular resistance, $C I$ cardiac index, $P H$ pulmonary hypertension, Prec- $P H$ pre-capillary $\mathrm{PH}, I p c-P H$ isolated post-capillary $\mathrm{PH}, \mathrm{Cpc}$ $\mathrm{PH}$ combined pre- and post-capillary $\mathrm{PH}$

\section{Right heart catheterization}

RHC was performed with the patients at rest without sedation, and PAP, PAWP, PVR, and cardiac output (CO) were obtained. The $\mathrm{CO}$ measured by the Fick method was used in the analysis and normalized by body surface area (BSA) to calculate the cardiac index (CI).

\section{Cardiac acoustic biomarkers (CABs)}

Baseline heart sounds and ECGs were recorded simultaneously by acoustic cardiography [24] before catheterization at rest. A Holter ECG recorder (AUDICOR AM-RT, Inovise Medical Inc, Portland, OR, USA) was used for acoustic cardiography a few hours after RHC. The recorder had three electrodes at the right upper, left upper, and left lower chest areas for electrocardiography, and two other electrodes with an accelerometer were placed at five different locations of the chest wall in the following three combinations: V3 and V4 (apex), V3 and the second left intercostal space (2L), and the third left intercostal space (3L) and the second right intercostal space (2R). Based on the empirical knowledge of auscultation, the data recorded at $\mathrm{V} 4$ and $3 \mathrm{~L}$ sites were used for later analysis to focus on extra heart sounds (S3 and S4) and S2 splitting, respectively. ECG and phonocardiogram (PCG) data for each location were approximately $1.5 \mathrm{~min}$ in length.
The heart sound categories, i.e., first, second, third, and fourth heart sounds (S1, S2, S3, and S4), synchronized with the ECG, were converted into the CABs of intensity, complexity [23], and strength [24] for each heart sound. The calculation methods for intensity and complexity are shown in Fig. 1 as an example of deriving S2Intensity and S2Complexity. SnIntensity quantifies the intensity of each heart sound category, where $n$ ranges from one to four, based on peak-to-peak amplitude on the PCG inside the segments of the heart sounds. In Fig. 1, split S2 vibration shows a wide and complex waveform in its filter bands with multiple peaks. The complexity of a waveform is quantified by SnComplexity, where the areas of valleys created by the peaks in high-frequency components inside the segment are summed. S3Strength and S4Strength are probability scores based on acoustic features reflecting the presence of an audible S3 and an audible S4 on standard auscultation. They range from 0 to 10 , and values above five indicate the existence of a clinically audible S3 or S4 in a 10-s recording.

\section{Statistical analysis}

Baseline numerical data are shown as means and standard deviation (SD). Categorical data are indicated as numbers and percentages. Characteristics of subjects across phenotypes of PH were compared by ANOVA or the $\chi^{2}$ test. The correlations between RHC parameters (mean PAP, PAWP, PVR, CI) and CABs (intensity, complexity, and strength) were evaluated by Pearson's correlation coefficients. Differences in measurement values on RHC and CABs among the 4 groups (Prec-PH, Ipc-PH, Cpc-PH, versus No-PH) were evaluated by $t$ test. To estimate the accuracy of differentiating the three $\mathrm{PH}$ types by $\mathrm{CABs}$, receiver operating characteristic (ROC) analysis was performed to test sensitivity and specificity with different thresholds, as well as the area under the curve (AUC). The thresholds of each parameter for evaluating accuracy were selected according to the maximum value of sensitivity- (1-specificity). The positive predictive value (PPV) and negative predictive value (NPV) were also calculated to evaluate diagnostic characteristics. All reported $p$ values are two tailed, and $p<0.05$ was taken to indicate significance. All statistical analyses were performed using JMP version 15 (SAS Institute, Cary, NC, USA).

\section{Results}

A total of 40 subjects were selected for this analysis from the database. The number of subjects in each phenotype of PH was as follows: Prec-PH, 5 cases; Ipc-PH, 5 cases; Cpc$\mathrm{PH}, 8$ cases; and No-PH, 22 cases. There were no significant differences in the subjects' characteristics among the $\mathrm{PH}$ phenotypes (Table 1). 
The correlations of the RHC parameters and CABs are presented in Table 2. Significant correlations were observed between mean PAP and S2Complexity (V4) or S3Strength (V4), PAWP and S3Intensity (V4) or S3Strength (3L, V4), PVR and S2Complexity (3L, V4), and CI and S1Intensity (3L) or S1Complexity (V4). RHC parameters and CABs of the PH phenotypes are shown in Tables 3 and 4. All RHC parameters were significantly different between $\mathrm{Cpc}-\mathrm{PH}$ and No-PH. Mean PAP and PVR in Prec-PH and mean PAP and PAWP in Ipc-PH were significantly higher than in No-PH (Table 3). S2Intensity, S2Complexity in Prec-PH, and S2, S3, and S4Intensity in Ipc-PH were significantly higher than in No-PH (both 3L, V4, Table 4). S3Strength was significantly higher in $\mathrm{Cpc}-\mathrm{PH}$ than in No-PH.
Diagnostic accuracy using CABs for the three types of PH by ROC analysis is shown in Table 5. The AUC of identifying Prec-PH from the other categories by S2Intensity or S2Complexity ranged from 0.674 to 0.720 , where sensitivity and specificity ranged from 0.400 to 0.800 and from 0.600 to 1.000 , respectively. Moreover, for identification of Ipc-PH by S2Intensity, S3Intensity, and S4Intensity, AUC ranged from 0.657 to 0.807 , where sensitivity and specificity varied from 0.800 to 1.000 and from 0.471 to 0.743 , respectively. The accuracy at the V4 measurement site was generally consistent with that at $3 \mathrm{~L}$. There were no clear improvements of sensitivity and specificity when different CABs were combined to identify Prec-PH and Ipc-PH, other than relatively higher values for NPV than for PPV.
Table $4 \mathrm{CAB}$ values by type of $\mathrm{PH}$

\begin{tabular}{|c|c|c|c|c|c|c|c|c|c|}
\hline \multirow[t]{2}{*}{$\mathrm{CAB}$} & \multirow[t]{2}{*}{ Type of PH } & \multicolumn{3}{|l|}{$3 \mathrm{~L}$} & \multirow[t]{2}{*}{$p$ vs No-PH } & \multicolumn{3}{|l|}{ V4 } & \multirow[t]{2}{*}{$p$ vs No-PH } \\
\hline & & Mean & SD & $n$ & & Mean & SD & $n$ & \\
\hline \multirow[t]{4}{*}{ S1Intensity } & No-PH & 2.9 & 3.8 & 22 & & 2.8 & 3.7 & 22 & \\
\hline & Prec-PH & 5.0 & 5.5 & 5 & 0.263 & 4.8 & 4.5 & 5 & 0.290 \\
\hline & Ipc-PH & 4.5 & 3.6 & 5 & 0.389 & 4.3 & 3.0 & 5 & 0.438 \\
\hline & Cpc-PH & 2.0 & 1.6 & 8 & 0.535 & 2.8 & 3.8 & 8 & 0.974 \\
\hline \multirow[t]{4}{*}{ S2Intensity } & No-PH & 1.4 & 1.3 & 22 & & 1.3 & 1.1 & 22 & \\
\hline & Prec-PH & 3.8 & 3.3 & 5 & 0.044 & 3.4 & 2.9 & 5 & 0.048 \\
\hline & Ipc-PH & 4.4 & 5.1 & 5 & 0.014 & 4.0 & 4.6 & 5 & 0.013 \\
\hline & Cpc-PH & 1.6 & 1.3 & 8 & 0.906 & 1.7 & 1.4 & 8 & 0.675 \\
\hline \multirow[t]{4}{*}{ S3Intensity } & No-PH & 0.3 & 0.3 & 22 & & 0.2 & 0.2 & 22 & \\
\hline & Prec-PH & 0.4 & 0.3 & 5 & 0.537 & 0.5 & 0.5 & 5 & 0.332 \\
\hline & Ipc-PH & 0.8 & 1.1 & 5 & 0.033 & 0.7 & 1.0 & 5 & 0.032 \\
\hline & Cpc-PH & 0.4 & 0.4 & 8 & 0.606 & 0.5 & 0.5 & 8 & 0.211 \\
\hline \multirow[t]{4}{*}{ S4Intensity } & No-PH & 0.2 & 0.2 & 21 & & 0.2 & 0.2 & 22 & \\
\hline & Prec-PH & 0.5 & 0.7 & 5 & 0.244 & 0.4 & 0.5 & 5 & 0.144 \\
\hline & Ipc-PH & 0.7 & 1.1 & 4 & 0.042 & 0.5 & 0.6 & 4 & 0.033 \\
\hline & Cpc-PH & 0.2 & 0.2 & 8 & 0.951 & 0.3 & 0.3 & 8 & 0.512 \\
\hline \multirow[t]{4}{*}{ S1Complexity } & No-PH & 5.4 & 2.8 & 22 & & 4.8 & 2.5 & 22 & \\
\hline & Prec-PH & 4.8 & 2.1 & 5 & 0.696 & 4.8 & 1.6 & 5 & 0.966 \\
\hline & Ipc-PH & 6.0 & 4.3 & 5 & 0.682 & 4.5 & 3.0 & 5 & 0.799 \\
\hline & $\mathrm{Cpc}-\mathrm{PH}$ & 4.7 & 2.9 & 8 & 0.549 & 3.8 & 2.5 & 8 & 0.306 \\
\hline \multirow[t]{4}{*}{ S2Complexity } & No-PH & 2.4 & 2.0 & 22 & & 2.1 & 1.6 & 22 & \\
\hline & Prec-PH & 4.9 & 3.5 & 5 & 0.032 & 5.3 & 3.5 & 5 & 0.003 \\
\hline & Ipc-PH & 2.4 & 1.8 & 5 & 0.994 & 3.0 & 1.9 & 5 & 0.357 \\
\hline & Cpc-PH & 3.8 & 2.3 & 8 & 0.145 & 3.5 & 1.9 & 8 & 0.083 \\
\hline \multirow[t]{4}{*}{ S3Strength } & No-PH & 3.8 & 2.1 & 22 & & 3.6 & 2.0 & 22 & \\
\hline & Prec-PH & 3.5 & 1.8 & 5 & 0.744 & 3.6 & 2.1 & 5 & 0.997 \\
\hline & Ipc-PH & 4.8 & 2.0 & 5 & 0.395 & 4.9 & 2.1 & 5 & 0.222 \\
\hline & Cpc-PH & 4.8 & 2.7 & 8 & 0.281 & 5.4 & 2.5 & 8 & 0.045 \\
\hline \multirow[t]{4}{*}{ S4Strength } & No-PH & 3.3 & 1.0 & 21 & & 3.3 & 0.8 & 22 & \\
\hline & Prec-PH & 3.4 & 1.3 & 5 & 0.812 & 3.1 & 1.4 & 5 & 0.749 \\
\hline & Ipc-PH & 2.7 & 1.1 & 4 & 0.469 & 2.8 & 1.3 & 4 & 0.538 \\
\hline & Cpc-PH & 4.2 & 2.5 & 8 & 0.127 & 4.0 & 2.8 & 8 & 0.327 \\
\hline
\end{tabular}

$C A B$ s cardiac acoustic biomarkers, $P H$ pulmonary hypertension, $P r e c-P H$ pre-capillary $\mathrm{PH}, I p c-P H$ isolated post-capillary $\mathrm{PH}, \mathrm{Cpc}-\mathrm{PH}$ combined pre- and post-capillary $\mathrm{PH}$ 


\section{Discussion}

The accuracy of CAB parameters to diagnose $\mathrm{PH}$ phenotypes was investigated. Several parameters measured by CABs were significantly correlated with RHC parameters. Previously, Chan et al. also reported significantly higher heart sound complexity in patients with PAH and a positive correlation with mean PAP [23]. In this analysis, significant correlations were observed between the other measurement values of heart sound parameters (intensity and strength) and the hemodynamic parameters (mean PAP, PAWP, and PVR) measured by RHC.

Moreover, significant differences were observed in CABs by the $\mathrm{PH}$ phenotypes. Therefore, the $\mathrm{CAB}$ values are supportive information indicating abnormal cardiopulmonary function and may be surrogate indicators for RHC parameters. Regarding the accuracy for PH typing of CABs, the AUC ranged from 0.674 to 0.720 for Prec-PH and 0.646 to 0.807 for Ipc-PH, and the AUC was 0.742 for Cpc-PH. These results were comparable to echocardiographic monitoring, where the diagnostic accuracy for typing of $\mathrm{PH}$ was reported to range from 0.689 to 0.8 [14-16]. CABs may provide healthcare practitioners an ambulatory method of monitoring PH-LHD patients that is more convenient and less expensive than echocardiography.

Since relatively high NPV values were observed in this dataset, CABs may also have potential to identify the No-PH population. In clinical settings, several scenarios using CABs can be implemented. For in-hospital use, CABs are positioned as a screening tool for patients requiring precise examination, such as echocardiographic measurement or RHC. For instance, a patient who has S2Intensity, S3Intensity or S4Intensity greater than or equal to $1.60,0.21$ or 0.10 , respectively at $3 \mathrm{~L}$ site, has suspected Ipc-PH. If a patient shows S2Intensity or S2Complexity greater than or equal to 4.13 or 3.57 , respectively at $3 \mathrm{~L}$ site, these criteria indicate possible Prec-PH. These patients should be referred for echocardiography or RHC (Fig. 2). For Ipc-PH and Cpc-PH screening, S3Intensity and S3Strength showed significant difference compared to No-PH, respectively. Since louder S3 are related to elevation of LVEDP, this correlation may be based on the nature of post-capillary PH due to left heart disease. On the other hand, the screening criterion of Prec$\mathrm{PH}$ are composed of S2-related CABs only. Pulmonic valve component of $\mathrm{S} 2$ sound can be affected by load in right ventricle due to pressure elevation occurred at pre-capillary and thus intensity and complexity are thought to be associated.

Since CABs can be easily obtained by non-invasive devices with ECG and PCG sensors, they may also be useful indicators for home tele-monitoring systems to evaluate worsening of heart failure. In such systems, patients can record daily $\mathrm{CABs}$ by themselves like blood pressure and weight. Long-term trend of CABs may provide useful information to detect worsening signs prior to an actual HF event and enables physicians to consider early and preventive intervention. This idea is purely conceptual at this point and further studies are needed to evaluate the effectiveness and usability of self-recorded CABs by patients at home.

There are several limitations in this analysis. The sample size was relatively small, and the $\mathrm{PH}$ groups were not matched by age and sex. However, there were no significant
Table 5 Diagnostic accuracy of CABs by the type of $\mathrm{PH}$

\begin{tabular}{|c|c|c|c|c|c|c|c|c|}
\hline Type of PH & $\mathrm{CAB}$ & Site & AUC & Threshold & Sensitivity & Specificity & PPV & NPV \\
\hline \multirow[t]{6}{*}{ Prec-PH } & \multirow[t]{2}{*}{ S2Intensity } & $3 \mathrm{~L}$ & 0.674 & 4.13 & 0.600 & 0.829 & 0.333 & 0.935 \\
\hline & & V4 & 0.674 & 3.18 & 0.600 & 0.800 & 0.300 & 0.933 \\
\hline & \multirow[t]{2}{*}{ S2Complexity } & $3 \mathrm{~L}$ & 0.697 & 3.57 & 0.800 & 0.600 & 0.222 & 0.955 \\
\hline & & V4 & 0.720 & 8.16 & 0.400 & 1.000 & 1.000 & 0.921 \\
\hline & \multirow[t]{2}{*}{ Combination } & $3 \mathrm{~L}$ & - & - & 0.800 & 0.486 & 0.174 & 0.947 \\
\hline & & V4 & - & - & 0.600 & 0.784 & 0.273 & 0.935 \\
\hline \multirow[t]{8}{*}{ Ipc-PH } & \multirow[t]{2}{*}{ S2Intensity } & $3 \mathrm{~L}$ & 0.686 & 1.60 & 0.800 & 0.714 & 0.286 & 0.962 \\
\hline & & V4 & 0.669 & 1.61 & 0.800 & 0.714 & 0.286 & 0.962 \\
\hline & \multirow[t]{2}{*}{ S3Intensity } & $3 \mathrm{~L}$ & 0.646 & 0.21 & 0.800 & 0.600 & 0.222 & 0.955 \\
\hline & & V4 & 0.657 & 0.26 & 0.800 & 0.600 & 0.222 & 0.955 \\
\hline & \multirow[t]{2}{*}{ S4Intensity } & $3 \mathrm{~L}$ & 0.662 & 0.10 & 1.000 & 0.471 & 0.182 & 1.000 \\
\hline & & V4 & 0.807 & 0.22 & 1.000 & 0.743 & 0.308 & 1.000 \\
\hline & \multirow[t]{2}{*}{ Combination } & $3 \mathrm{~L}$ & - & - & 1.000 & 0.371 & 0.185 & 1.000 \\
\hline & & V4 & - & - & 0.800 & 0.571 & 0.211 & 0.952 \\
\hline Cpc-PH & S3Strength & V4 & 0.742 & 3.15 & 1.000 & 0.469 & 0.320 & 1.000 \\
\hline
\end{tabular}

$C A B s$ cardiac acoustic biomarkers, $P H$ pulmonary hypertension, $P r e c-P H$ pre-capillary $\mathrm{PH}, I p c-P H$ isolated post-capillary $\mathrm{PH}, C p c-P H$ combined pre- and post-capillary $\mathrm{PH}, P P V$ positive predictive value, $N P V$ negative predictive value 


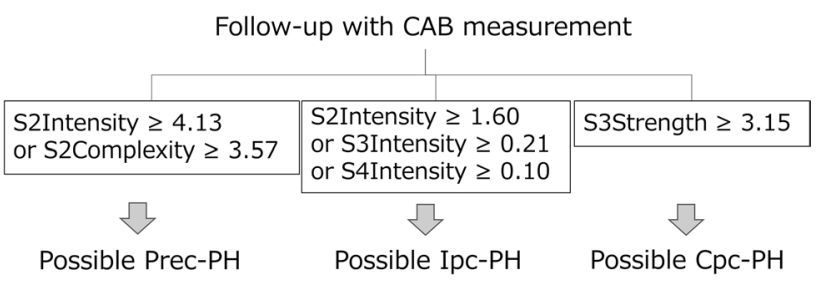

Fig. 2 Flowchart for phenotype screening for pulmonary hypertension in the clinical setting. $C A B S$ cardiac acoustic biomarkers, $P H$ pulmonary hypertensions, $P r e c-P H$ pre-capillary $\mathrm{PH}, I p c-P H$ isolated post-capillary $\mathrm{PH}, \mathrm{Cpc}-\mathrm{PH}$ combined pre- and post-capillary $\mathrm{PH}$

differences between the groups, and significant relationships were observed between CABs and RHC parameters. Furthermore, the general information regarding ICU inpatients were limited; therefore, the differences of hemodynamic and respiratory condition between inpatients and outpatients were unknown and may have had impact on CABs. Second, echocardiography was not measured simultaneously in this dataset. Therefore, a prospective study with parallel measurement should be performed. Third, this result cannot be directly applied to patients with positive pressure ventilation due to lack of ventilated cases in the present study.

In conclusion, $\mathrm{CABs}$ may provide an ambulatory method with home-monitoring friendliness which is more convenient than standard examinations to identify presence of $\mathrm{PH}$ and its phenotypes.

Acknowledgements The authors would like to express their sincere acknowledgement to Inovise Medical for providing the data, and to Peter Bauer and Patti Arand for their advice.

Author contributions Study concept and design: NY, NK, TK, TK and KN. Statistical analysis: TK. Drafting of the manuscript: NY and TK. Data interpretation: NY and TK. Critical revision of the manuscript for important intellectual content, and approval of the final version: NY, NK, TK, TK and KN.

Funding This work was supported by Asahi Kasei Corporation.

Data availability The datasets generated during and/or analyzed during the current study are not publicly available due to confidentiality agreements with research collaborators. Therefore, supporting data can only be made available to researchers subject to a non-disclosure agreement.

\section{Declarations}

Conflict of interest N.K. has an endowed chair from Asahi Kasei Corporation since 2017. N.K. and K.N. received consulting fees from Asahi Kasei Corporation. N.Y. and T.K. are employees of Asahi Kasei Corporation.

Ethics approval This study was conducted in compliance with the Declaration of Helsinki. The study protocol was reviewed and approved by the ethics committee of Saga University, Japan. Written, informed consent was obtained from all subjects before measurement of baseline data. The need to obtain consent for participation in this study was waived due to the retrospective nature of the study.

Open Access This article is licensed under a Creative Commons Attribution 4.0 International License, which permits use, sharing, adaptation, distribution and reproduction in any medium or format, as long as you give appropriate credit to the original author(s) and the source, provide a link to the Creative Commons licence, and indicate if changes were made. The images or other third party material in this article are included in the article's Creative Commons licence, unless indicated otherwise in a credit line to the material. If material is not included in the article's Creative Commons licence and your intended use is not permitted by statutory regulation or exceeds the permitted use, you will need to obtain permission directly from the copyright holder. To view a copy of this licence, visit http://creativecommons.org/licenses/by/4.0/.

\section{References}

1. Vachiéry JL, Adir Y, Barberà JA, Champion H, Coghlan JG, Cottin V, De Marco T, Galiè N, Ghio S, Gibbs JS, Martinez F, Semigran M, Simonneau G, Wells A, Seeger W (2013) Pulmonary hypertension due to left heart diseases. J Am Coll Cardiol 62:D100-D108

2. Yancy CW, Jessup M, Bozkurt B, Butler J, Casey DE Jr, Drazner MH, Fonarow GC, Geraci SA, Horwich T, Januzzi JL, Johnson MR, Kasper EK, Levy WC, Masoudi FA, McBride PE, McMurray JJ, Mitchell JE, Peterson PN, Riegel B, Sam F, Stevenson LW, Tang WH, Tsai EJ, Wilkoff BL, American College of Cardiology Foundation/American Heart Association Task Force on Practice Guidelines (2013) 2013 ACCF/AHA guideline for the management of heart failure: a report of the American College of Cardiology Foundation/American Heart Association Task Force on Practice Guidelines. Circulation 128:e240-327

3. Guazzi M, Borlaug BA (2012) Pulmonary hypertension due to left heart disease. Circulation 126:975-990. https://doi.org/10.1161/ CIRCULATIONAHA.111.085761

4. Melenovsky V, Hwang SJ, Lin G, Redfield MM, Borlaug BA (2014) Right heart dysfunction in heart failure with preserved ejection fraction. Eur Heart J 35:3452-3462

5. Vachiéry JL, Tedford RJ, Rosenkranz S, Palazzini M, Lang I, Guazzi M, Coghlan G, Chazova I, De Marco T (2019) Pulmonary hypertension due to left heart disease. Eur Respir J 53:1801897

6. Galiè N, Torbicki A, Barst R, Dartevelle P, Haworth S, Higenbottam T, Olschewski H, Peacock A, Pietra G, Rubin LJ, Simonneau G, Priori SG, Garcia MA, Blanc JJ, Budaj A, Cowie M, Dean V, Deckers J, Burgos EF, Lekakis J, Lindahl B, Mazzotta G, McGregor K, Morais J, Oto A, Smiseth OA, Barbera JA, Gibbs S, Hoeper M, Humbert M, Naeije R, Pepke-Zaba J (2004) Guidelines on diagnosis and treatment of pulmonary arterial hypertension. The Task Force on Diagnosis and Treatment of Pulmonary Arterial Hypertension of the European Society of Cardiology. Eur Heart J 25:2243-2278

7. Simonneau G, Montani D, Celermajer DS, Denton CP, Gatzoulis MA, Krowka M, Williams PG, Souza R (2019) Haemodynamic definitions and updated clinical classification of pulmonary hypertension. Eur Respir J 53:1801913

8. Gerges M, Gerges C, Pistritto AM, Lang MB, Trip P, Jakowitsch J, Binder T, Lang IM (2015) Pulmonary hypertension in heart failure. Epidemiology, right ventricular function, and survival. Am J Respir Crit Care Med 192:1234-1246

9. Abraham WT, Adamson PB, Bourge RC, Aaron MF, Costanzo MR, Stevenson LW, Strickland W, Neelagaru S, Raval N, Krueger S, Weiner S, Shavelle D, Jeffries B, Yadav JS, CHAMPION Trial 
Study Group (2011) Wireless pulmonary artery haemodynamic monitoring in chronic heart failure: a randomised controlled trial. Lancet 377:658-666

10. Matthay MA, Chatterjee K (1988) Bedside catheterization of the pulmonary artery: risks compared with benefits. Ann Intern Med 109:826-834

11. Boyed KD, Thomas SJ, Gold J, Boyed AD (1983) A prospective study of complications of pulmonary artery catheterization in 500 consecutive patients. Chest 84:245-249

12. Galie N, Humbert M, Vachiery JL, Gibbs S, Lang I, Torbicki A, Simonneau G, Peacock A, Vonk Noordegraaf A, Beghetti M, Ghofrani A, Gomez Sanchez MA, Hansmann G, Klepetko W, Lancellotti P, Matucci M, McDonagh T, Pierard LA, Trindade PT, Zompatori M, Hoeper M, ESC Scientific Document Group (2016) 2015 ESC/ERS Guidelines for the diagnosis and treatment of pulmonary hypertension: The Joint Task Force for the Diagnosis and Treatment of Pulmonary Hypertension of the European Society of Cardiology (ESC) and the European Respiratory Society (ERS): Endorsed by: Association for European Paediatric and Congenital Cardiology (AEPC), International Society for Heart and Lung Transplantation (ISHLT). Eur Heart J 37:67-119

13. Rudski LG, Lai WW, Afilalo J, Hua L, Handschumacher MD, Chandrasekaran K, Solomon SD, Louie EK, Schiller NB (2010) Guidelines for the echocardiographic assessment of the right heart in adults: a report from the American Society of Echocardiography endorsed by the European Association of Echocardiography, a registered branch of the European Society of Cardiology, and the Canadian Society of Echocardiography. J Am Soc Echocardiogr 23:685-713

14. Opotowsky AR, Ojeda J, Rogers F, Prasanna V, Clair M, Moko L, Vaidya A, Afilalo J, Forfia PR (2012) A simple echocardiographic prediction rule for hemodynamics in pulmonary hypertension. Circ Cardiovasc Imaging 5:765-775

15. D'Alto M, Romeo E, Argiento P, Pavelescu A, Mélot C, D'Andrea A, Correra A, Bossone E, Calabrò R, Russo MG, Naeije R (2015) Echocardiographic prediction of pre-versus postcapillary pulmonary hypertension. J Am Soc Echocardiogr 28:108-115

16. Venkateshvaran A, Hamade J, Kjellström B, Lund LH, Manouras A (2019) Doppler estimates of pulmonary vascular resistance to phenotype pulmonary hypertension in heart failure. Int J Cardiovasc Imaging 35:1465-1472

17. Bacal F, de Freitas AF Jr, Moreira LF, Fiorelli AI, Mangini S, Abuhab A, de Lima Oliveira J Jr, Santos RH, Stolf NA, Bocchi
EA (2010) Validation of a cutoff value on echo Doppler analysis to replace right heart catheterization during pulmonary hypertension evaluation in heart transplant candidates. Transplant Proc 42:535-538

18. D'Alto M, Romeo E, Argiento P, D'Andrea A, Vanderpool R, Correra A, Bossone E, Sarubbi B, Calabrò R, Russo MG, Naeije R (2013) Accuracy and precision of echocardiography versus right heart catheterization for the assessment of pulmonary hypertension. Int J Cardiol 168:4058-4062

19. Hummel YM, Liu LCY, Lam CSP, Fonseca-Munoz DF, Damman K, Rienstra M, van der Meer P, Rosenkranz S, van Veldhuisen DJ, Voors AA, Hoendermis ES (2017) Echocardiographic estimation of left ventricular and pulmonary pressures in patients with heart failure and preserved ejection fraction: a study utilizing simultaneous echocardiography and invasive measurements. Eur J Heart Fail 19:1651-1660

20. Correale M, Tricarico L, Padovano G, Ferraretti A, Monaco I, Musci RL, Galgano G, Di Biase M, Brunetti ND (2019) Echocardiographic score for prediction of pulmonary hypertension at catheterization: the Daunia Heart Failure Registry. J Cardiovasc Med 20:809-815

21. Burkhoff D, Bailey G, Gimbel JR (2020) Characterization of cardiac acoustic biomarkers in patients with heart failure. Ann Noninvasive Electrocardiol 25:e12717

22. Dennis A, Michaels AD, Arand P, Ventura D (2010) Noninvasive diagnosis of pulmonary hypertension using heart sound analysis. Comput Biol Med 40:758-764

23. Chan W, Woldeyohannes M, Colman R, Arand P, Michaels AD, Parker JD, Granton JT, Mak S (2013) Haemodynamic and structural correlates of the first and second heart sounds in pulmonary arterial hypertension: an acoustic cardiography cohort study. BMJ Open 3:e002660

24. Dillier R, Zuber M, Arand P, Erne S, Erne P (2011) Assessment of systolic and diastolic function in asymptomatic subjects using ambulatory monitoring with acoustic cardiography. Clin Cardiol 34:384-388

Publisher's Note Springer Nature remains neutral with regard to jurisdictional claims in published maps and institutional affiliations. 